\title{
Theoretical and philosophical approaches of Russian management thought to the correlation of occupational reasonability and human factor
}

\author{
Aleksandr P. Birukov ${ }^{1 *}$, Irina S. Brikoshina ${ }^{1}$, Elena A. Vikhodtseva $^{1}$, \\ Artem $G$. Geokchakyan ${ }^{1}$, and Elena $V$. Nikitina ${ }^{1}$ \\ ${ }^{1}$ State University of Management, Department of project management, Moscow, Russia
}

\begin{abstract}
One of the fundamental problems in management is the issue of correlation of occupational rationality and human factor. The highest recognition of this issue was achieved in the Russian management thought in the early 1900s. The authors have concentrated their attention on the Russian management thought, since it is studied less in comparison with classical Western management schools. This article analyzes the works by the major philosophers and theoreticians of management, their approaches and attitudes to the mentioned issue are considered, the main results of conferences on scientific organization of labor held in the USSR are studied. The main aim of the article is retrospective analysis and systematization of approaches of the Russian scientists to the correlation between occupational rationality and human capital. The results of the study are arranged in the form of correlation matrix of various sides and attitudes on this issue in the works by various Russian philosophers of management. It should be mentioned that solution to this problem is relevant at present, since digitization minimizes the significance and opportunities of human factor.
\end{abstract}

Keywords: history and philosophy of management, management rationalization, human capital, management.

\section{Introduction}

Management thought in the course of its history faced numerous scientific and methodological problems and contradictions. Researchers involved in the issues of management understand fairly well that such contradictions advance the science, since the management is a social humanitarian science and its development directly depends on the thoughts and attitudes of researchers. However, in order to use these attitudes in practice, they should be scientifically substantiated. Analysis of theoretical and philosophical provisions of the management thought of various schools and scientists is the basis for development of modern management [1]. The management science is based mainly on the concepts by F. Taylor, J. H. Fayol, H. Ford and more recent Western schools [2]. Nowadays the researchers agree that the development of management terminated, and new concepts are

\footnotetext{
* Corresponding author: kaf up@guu.ru
} 
just reconsideration of the existing ones. In this regard the issue arises to determine new trends of management thought [3].

Peculiar interest is attracted to consideration of philosophical attitudes on the correlation between occupational rationality and human factor. A precondition of the study is the results of analysis of programs of historical management disciplines; thus, it is possible to conclude that the Russian management thought is being analyzed very moderately. This study is aimed at analysis of theoretical and philosophical provisions and attitudes on the mentioned problem in the Russian management thought. A scientific novelty is the short retrospective overview of the main provisions of the Russian management thought, as well as arrangement of the correlation matrix of occupational rationality and human factor [4].

\section{Methods}

The presented overview of the Russian management thought refers to the early 1900s. Numerous scientific trends were developed at that time, some of them competed with worldfamous management trends. This work critically analyzes of the works by A.A. Bogdanov, V.M. Bekhterev, O.A. Ermanskii, A.K. Gastev, P.M. Esmanskii, N.A. Vitke, F.R. Dunaevskii, P.M. Kerzhentsev, E.F. Rozmirovich, M.A. Yurovskaya [5]. In addition, the proceedings of the 1st and the 2nd USSR conferences on scientific organization of labor and production are considered [6].

In addition to scientific and theoretical studies, research institutes and laboratories were highly popular, which were the centers of rationalization. Close relation between management thought and production was unique; thus, numerous provisions were verified immediately. Production supplied information for further studies. Such institutes and laboratories presented mechanism of management development by means of synergistic effect of scientific development, their practical verification, and expert training [7].

\section{Results}

On the basis of the performed study, it could be mentioned that the considered problem has two opposite sides:

- $\quad$ rationalization, optimization, and improvement of production process as such;

- accounting for human capital, reference to psychophysiological and psychosocial features of person.

Herewith, some researchers adhered to this or that side of the problem, the other tried to achieve the golden mean. The results can be illustrated in the form of respective matrix (Fig. 1). 


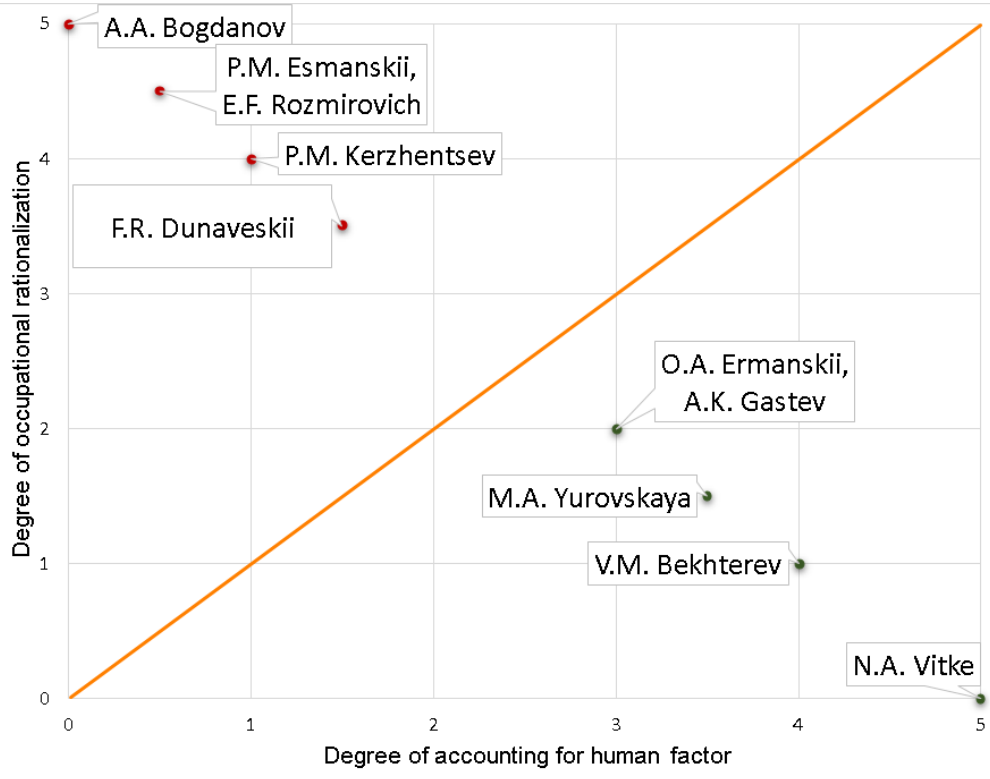

Fig. 1. Matrix of correlation between opposite sides of solution to the problem of occupational rationality and human factor in the works by Russian researchers and philosophers of management. Compiled by the authors based on the experimental results.

The matrix demonstrates prevailing of one or another side in solution to the issue in the approaches of the Russian philosophers of management in early 1900s. The scores reflect the degree of prevailing of this or that side. According to the authors' assumption and aiming at systematization of the considered attitudes, the sum of the point coordinates could not exceed the maximum degree of 5 . The red points reflect prevailing of the first side of the problem, the green points are referred to the second side.

\section{Discussion}

A.A. Bogdanov was one of the first Russian philosophers of management, who believed that there existed common laws and approaches used for management of any processes in nature, society, economy. In this regard, the specificity of management object should not be very important for selection of management methods. A.A. Bogdanov was talking about organizational elements and importance of organizational integrity, which was higher than the sum of its single elements. In these concepts, the footprints of system approach and synergy effect can be traced [8].

Less global approach to generalization of management objects was proposed by P.M. Esmanskii and P.M. Kerzhentsev, who highlighted social objects in overall family and developed general approaches to management of human personnel. Herewith, P.M. Kerzhentsev believed that the existing scientific and practical experience could be transferred from some spheres to other.

Another philosopher, F.R. Dunaevskii, was talking about necessity to use integrated approach upon analysis of management problems, where he considered a company as a single whole system. Only in integrity and complexity he saw possibility of a company to reach efficiency. As in the A.A. Bogdanov's concepts, the footprints of system approach can be traced. An interesting proposal is the concept of administrative capacitance, nowadays its essence is known as the span of management. 
In addition, F.R. Dunaevskii paid great attention to the case method (a well-known situational approach), mentioning that each coincidence was unique; thus, one and the same decision in some situations could be successful and disastrous in other cases.

The psychophysiological approach by V.M. Bekhterev is cardinally opposite. He believed that a worker should be in the center of any management system: a person with peculiar abilities, skills, physical and psychological boundaries. He criticized Western concepts of management for their neglect of human labor, for glorification of rationalizing methods to use machines. As the main task of management, he mentioned necessity to train a worker to use his potential with the highest efficiency, though, in the frames of organism capabilities. Any human activity should adhere to health saving mode, which does not mean refusal from labor but its execution in the frames of capabilities.

O.A. Ermanskii in his concepts shifted the A.A. Bogdanov's ideas to the background and developed the concept of optimum, the essence of which was in detection of optimum combination of labor consumptions and achieved results. In his studies, he underlined the importance of human capital, without which no production would be possible [9]. A human is the main factor of any production. However, being fascinated with the concepts of optimization, the researcher considers only physiological side of a human without consideration of social and psychological features, considered by V.M. Bekhterev.

While developing these concepts, M.A. Yurovskaya was talking about the theory of distribution of labor resources on the basis of their psychological and physical abilities to profession (psychotechnology). Herewith, when most humans will be engaged in the professions of their predisposition, the national labor efficiency will be maximum.

The peak of development of psychological concepts is the social approach by N.A. Vitke. He believed that the essence of organizational activity was in construction and mastering human relations, formation of favorable social psychological climate, orientation of human energy to achievement of definite target [10].

The concepts of N.A. Vitke and V.M. Bekhterev are the prototype of schools of human relations and behavioral sciences. Unfortunately, these concepts were accepted negatively in the USSR; at present, all the world knows M. Follet and E. Mayo as the founders of human relations movement in science [11].

One of the most prominent representatives of the Russian management was A.K. Gastev, who mostly shared Western concepts, though introduced human factor into them, which should support the gravity center of management [12]. He substantiated the decisive role of human factor in production processes, which could not be compensated by any technical decisions. An interesting idea was identification of specificity of production and management labor [13].

E.F. Rozmirovich was talking about existence of common properties of all types of processes, which could be subdivided into separate procedures, mechanized, then their sequence could be determined, with the notion of personality reduced to minimum. This concept reached its peak in transition from management of humans to management of things. At that time this concept was criticized; however, upon digitization, it became obvious that it was quite promising [14].

\section{Conclusion}

It should be mentioned in conclusion that in the Russian management thought, high attention was paid, on the one hand, to rationalization and optimization of production process and, on the other hand, to the role of human capital and psychology of management. It is impossible to answer this question unambiguously. All attitudes could and should be understood, since management is a humanitarian science, it is being developed while its ideas and concepts are 
being developed. The described issue is relevant in modern management, here and now, it requires further, more detailed analysis [15].

Moreover, it is obvious that numerous interesting concepts of the Russian philosophers of management were undeservedly forgotten; however, subsequently, they were intensively developed in other countries.

\section{References}

1. V.I. Marshev, Management Sciences in Russia, 1, 6-16 (2016)

2. E.P. Turbina, Yu.S. Permenova, Journal of Shadrinsk State Pedagogical University, 2(26), 138-144 (2015)

3. A.G. Geokchakyan, Osobennosti formirovaniya rossiyskoy modeli menedzhmenta [Features of the formation of the Russian model of management], in Materials of the 31st All-Russian scientific conference Reforms in Russia and problems of management, 275-277 (State University of Management, Moscow, 2016)

4. D.G. Rodionova, Kultura: Teoriya i Praktika, 1(34), 13 (2020)

5. M.A. Bogatyrev, Terra Economicus, 7(2), 85-90 (2009)

6. S.P. Kostrikov, Bulletin of the University, 18, 59-68 (2014)

7. E.B. Koritsky, Russian Journal of Management, 3(1), 127-144 (2005)

8. M.V. Loktionov, Philosophy of Science and Technology, 21(2), 80-96 (2016)

9. A.D. Kuzmichev, Management Sciences in Russia, 4, 6-13 (2016)

10. G.V. Nintsiyeva, Izvestiya Sankt-Peterburgskogo Gosudarstvennogo Ekonomicheskogo Universiteta, 2(104), 108-111 (2017)

11. S.A. Ilinykh, Ideas and Ideals, 1(2(24)), 94-106 (2015)

12. Yu.P. Nadekhina, Bulletin of the University, 18, 99-104 (2014)

13. E.V. Starikova, G.M. Preobrazhensky, Journal of Wellbeing Technologies, 3(30), 83$92(2018)$

14. I. Brikoshina, A. Birukov, A. Geokchakyan, Lecture Notes in Networks and Systems, 155, 1614-1622 (Springer, Cham, 2020)

15. A.L. Lazutkina, T.E. Lebedeva, Innovatsionnaya Ekonomika: Perspektivy Razvitiya I Sovershenstvovaniya, 8(34), 200-207 (2018) 